\title{
El deslizamiento gravitatorio de Guando (Tolima, Colombia): características morfoestructurales y consecuencias de su interpretación
}

\author{
Eduardo Antonio Rossello $^{1^{*}}$ (D) ; José Luis Saavedra² \\ Forma de citar: Rossello, E.A.; Saavedra, J.L. (2020). El deslizamiento gravitatorio de Guando (Tolima, \\ Colombia): características morfoestructurales y consecuencias de su interpretación. Boletín de Geología, 42(3), \\ 151-170. https://doi.org/10.18273/revbol.v42n3-2020007
}

\begin{abstract}
Resumen
Las áreas montañosas con fuertes pendientes topográficas suelen acusar fenómenos de deslizamientos gravitatorios someros que atenúan la prominencia del relieve como el ocurrido en Guando. La naturaleza multicomposicional de los volúmenes rocosos involucrados, la incidencia climática y la acción de la sismicidad pueden desencadenar deslizamientos que ajustan la topografía a niveles de mayor estabilidad. De este modo, la interpretación tectónica compresional frecuentemente responsable y característica de estos relieves está afectada por rasgos atribuidos a fenómenos más recientes y someros de tipo gravitatorio. Así, se puede involucrar dentro de un mismo proceso deformativo a los cabalgamientos con los deslizamientos gravitatorios si se los considera cronológicamente contemporáneos. Si se localizan sobre objetivos exploratorios infrayacentes al ser atravesados con sondeos, pueden producirse bloqueos y colapsos de las herramientas de perforación en función de los desplazamientos que ocurren sobre las superficies subhorizontales del deslizamiento. El objetivo de este trabajo es describir rasgos morfoestructurales topográficos y de subsuelo característicos de los desplazamientos gravitatorios involucrados en la interpretación estructural compresional convencional y los problemas técnicos que pueden generar en las actividades exploratorias. Al respecto, se proporciona una descripción 3D del caso del Campo Guando en la Cuenca Superior del Magdalena (Colombia) con un ejemplo real de las posibles causas y consecuencias de esta problemática.
\end{abstract}

Palabras clave: Deslizamiento gravitatorio; Interpretación estructural; Tectónica; Campo Guando; Colombia.

\section{The gravitational slumping of Guando (Tolima, Colombia): structural characteristics and consequences in its tectonic interpretation}

\begin{abstract}
The mountainous areas with steep topographic slopes tend to show shallow gravitational landslides that attenuate the prominence of the relief, as occurred in Guando. The multicompositional nature of the rocky volumes involved, the climatic incidence and the action of seismicity can trigger landslides that adjust the topography to levels of greater stability. Thus, the frequently responsible and characteristic compressional tectonic interpretation of these reliefs is affected by features attributed to more recent and shallow gravitational phenomena. Thus, it is possible to involve within the same deformative process the thrusting with the gravitational slides if they are considered chronologically contemporary. If they are located on underlying exploratory targets when drilled through, drilling tools may crash and collapse depending on the displacements magnitudes that occur on the sub-horizontal surfaces of the slide. The objective of this work is to describe topographic and subsoil morphostructural features characteristic of the gravitational displacements involved in conventional compressional structural interpretation and the technical problems that can be generated in exploratory activities. In this regard, a 3D description of the Campo Guando case in the Upper Magdalena Basin (Colombia) is provided with a real example of the possible causes and consequences of this problem.
\end{abstract}

Keywords: Gravitational slumping, Structural interpretation, Tectonics, Guando Field, Colombia.

\footnotetext{
${ }^{1}$ Consejo Nacional de Investigaciones Científicas y Técnicas - Instituto de Geología y Ciencias Básicas de Buenos Aires, Facultad de Ciencias Exactas y Naturales, Universidad de Buenos Aires, Buenos Aires, Argentina. (*) ea_rossello@yahoo.com.ar

${ }^{2}$ HOCOL S.A. Bogotá, Colombia. jose.saavedra@hocol.com.co
} 


\section{Introducción}

En la interpretación tectónica de áreas montañosas con fuertes pendientes topográficas es muy habitual la consideración de cabalgamientos, como los principales responsables de la generación del relieve, tanto por modelos de tectónica gruesa o fina (Pfiffner, 2017). Además, como consecuencia de la inestabilidad de sus laderas suelen acusar fenómenos de deslizamientos o movimientos gravitatorios someros en la terminología de Alcántara-Ayala (2000), landslides de Sharpe (1938) o slumping según Alsop et al. (2017). Así, se atenúan las pendientes del relieve al lograrse condiciones de mayor estabilidad al adecuarse a los niveles de base (Easterbrook, 1993). De este modo, la interpretación tectónica convencional suele estar afectada y obliterada por rasgos atribuidos a fenómenos más recientes de tipo gravitatorio. Por otro lado, cuando estos sectores se localizan sobre objetivos exploratorios se afectan la estabilidad de las instalaciones logísticas que, el caso de los sondeos que los atraviesan, se puede producir, entre los riesgos descriptos por Glade et al. (2012), bloqueos y colapsos en función de los desplazamientos y modificaciones del terreno que ocurren sobre las superficies subhorizontales del desplazamiento.

El objetivo de este trabajo es la descripción de los principales rasgos morfoestructurales de los desplazamientos gravitatorios superpuestos al cabalgamiento Boquerón en el Campo Guando, como un ejemplo que puede extrapolarse a situaciones con ambientes estructurales semejantes. También, se proporciona una descripción resumida con información de superficie y subsuelo del Campo Guando en la Cuenca Superior del Magdalena (Colombia) como un ejemplo real de las geoformas características del deslizamiento gravitatorio y sus posibles causas y consecuencias de esta problemática en las actividades exploratorias (Schuster et al., 2002). De esta manera, se propone un nuevo modelo estructural del Campo Guando (Buitrago, 1994; Higuera, 2012), que tiene en cuenta las características integrales del cabalgamiento Boquerón y los últimos acontecimientos deformativos debidos al deslizamiento Guando (Figura 1).

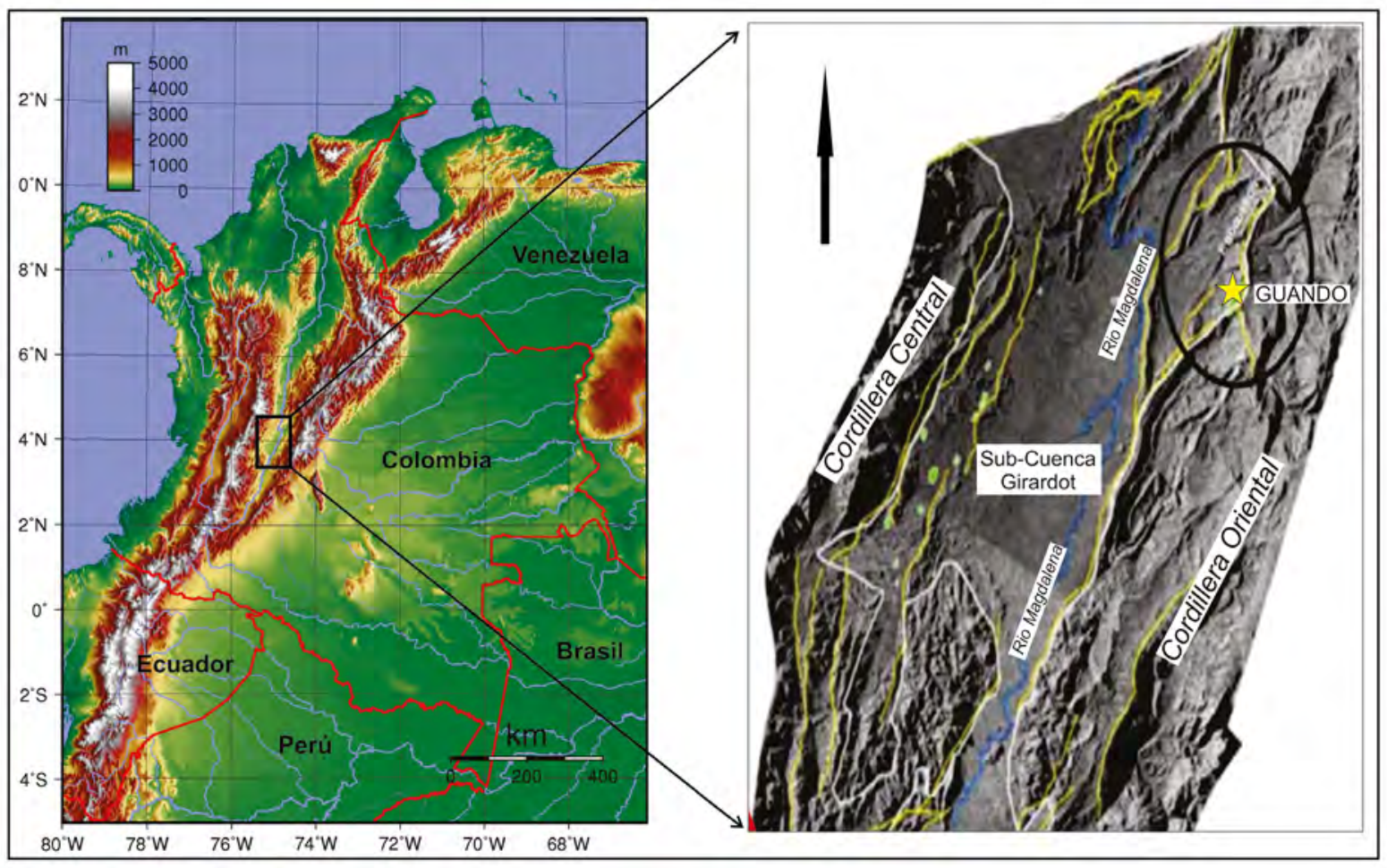

Figura 1. Localización del Campo Guando (estrella amarilla) perteneciente a la Sub-Cuenca Girardot del Valle Superior del Magdalena (Tolima, Colombia). 


\section{Marco teórico}

Los deslizamientos gravitatorios son fenómenos de la superficie terrestre que ocurren en una amplia variedad de entornos geológicos caracterizados por relieves marcados, sean estos generados por complejos de subducción, arcos volcánicos, cinturones transformantes y/o ambientes de intraplaca (Cruden y Varnes, 1996). De esta manera, son comunes en cualquier lugar de la superficie de la Tierra donde existen pendientes topográficas inestables con valores que varían desde escasos hasta muchos grados de inclinación, de acuerdo con los comportamientos mecánicos de los materiales afectados.

Un deslizamiento gravitatorio o movimiento de terreno es una forma de inestabilidad que se caracteriza por el desplazamiento por su propio peso de un volumen de materiales rocosos en un trecho relativamente corto a lo largo de una pendiente. El movimiento se caracteriza por el deslizamiento de los volúmenes a partir de una superficie de despegue con geometría plana y/o cóncava que lo desvincula del substrato excluido del proceso deformativo.

Laspropiedades físicas del volumen desplazado dispuesto directamente sobre una superficie inclinada juegan también un papel importante en el desencadenamiento o no del deslizamiento por tales pendientes bajo la influencia de la componente tangencial de la gravedad. El volumen rocoso está en condiciones de movilizarse cuando la superficie de desplazamiento forma un ángulo de más de $45^{\circ}$ con respecto a la horizontal, porque la componente normal de la gravedad será menor que la componente tangencial (Girty, 2009). Entonces, al ser menor componente normal gravitatoria disminuye la resistencia sobre la superficie infrayacente porque el coeficiente de rozamiento es menor y, por lo tanto, la probabilidad de deslizamiento aumentará considerablemente (Figura 2).
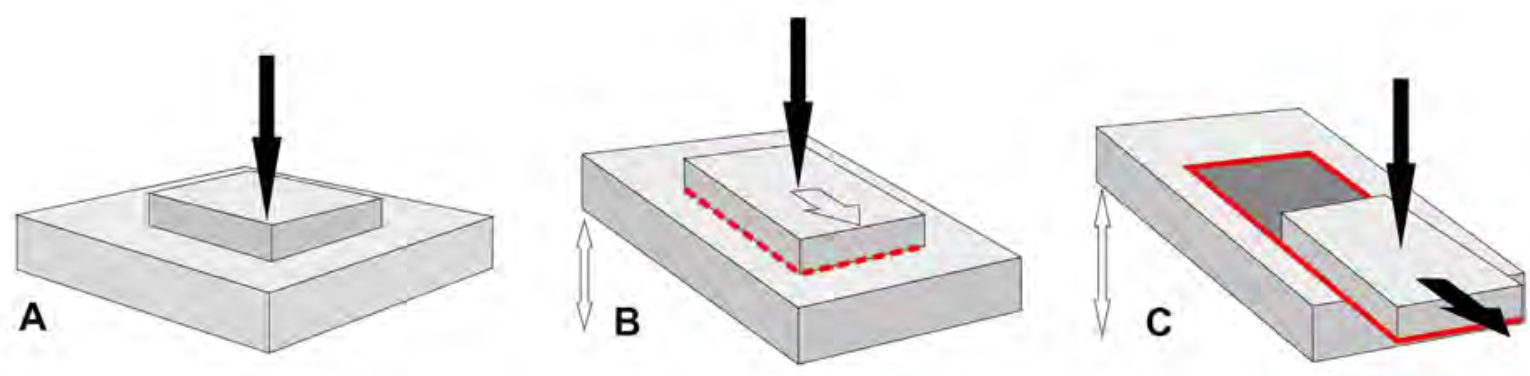

Figura 2. Condiciones de estabilidad en función de las relaciones angulares entre la fuerza de gravedad y la inclinación del plano de deslizamiento. A. $90^{\circ}$ condiciones de estabilidad. B. Inclinado a menos de $45^{\circ}$. C. Inclinado a más de $45^{\circ}$ más inestable.

En el caso que los deslizamientos gravitatorios involucren materiales con respuestas mecánicas competentes que le otorgan una mayor cohesión interna y resistencia a la deformación pueden dificultar su movilidad hacia sectores más deprimidos a pesar de disponerse sobre pendientes muy pronunciadas. En el caso que se produzcan deslizamientos debido a una pendiente suficientemente pronunciada como para que los materiales cedan a la gravedad, aquellos de naturaleza muy competente lo hará como bloques coherentes que caerán basculándose uniformemente y conservando la integridad individual cuesta abajo (Ng y Chew, 2019).

En cambio, si las características del material a movilizar son más incompetentes y, en consecuencia, con menor resistencia a la deformación, se deslizará por superficies de deslizamientos con pendientes, incluso, con pequeñas inclinaciones. Así, los materiales incompetentes tenderán a movilizarse en pendientes descendentes fluyendo con características más plásticas y modificando totalmente sus características internas primarias (Figura 3).

Existen numerosas clasificaciones de los deslizamientos gravitatorios en la literatura científica y técnica, donde la primera y de amplia aceptación fue la de Sharpe (1938). Con posterioridad aparecieron las de Varnes (1958, 1978), Nemčok et al. (1972), Hutchinson (1988) y, más recientemente, las de Dikau et al. (1996), Sassa (1999), Cruden y Varnes (1996) y AlcántaraAyala et al. (2014), entre otras. En general, la mayoría de clasificaciones lo hacen en función; a) del tipo de material existente antes del deslizamiento (roca, tierra, lodo y escombros) y b) del tipo de movimiento dominante (caída, deslizamiento, propagación y flujo). 

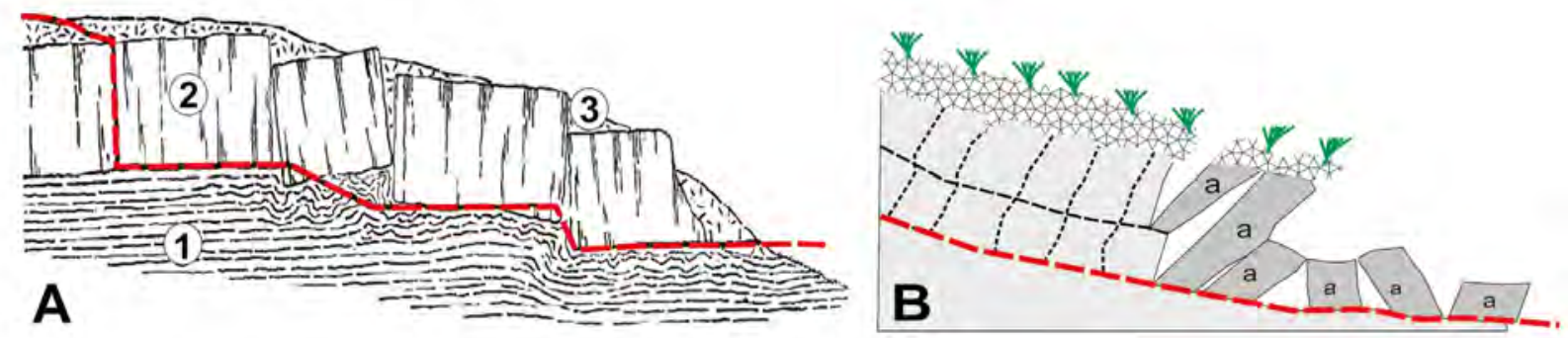

Figura 3. Esquemas de deslizamientos gravitatorios de materiales competentes. A. Deslizamiento de bloques (2) sobre una pendiente suave de un substrato deformable (1) y cobertura (3) posterior (tomado de Nemčok et al., 1972). B. Deslizamiento de bloques con caídas y basculamientos variables (a) sobre una pendiente mayor (modificado de Cruden y Varnes, 1996).

Los mecanismos de inestabilidad y la tipología del movimiento suelen establecerse una vez que la rotura ha tenido lugar, es decir, basándose en su cinemática. En este sentido, los mecanismos y condiciones que dan lugar a la rotura de una ladera no se corresponden, en general, con los que gobiernan la propagación del volumen deslizante una vez liberado, siendo éstos los que determinan la denominación del movimiento. Varnes (1958) agrupa como deslizamientos de tierra (landslice) a todo movimiento descendente hacia afuera de los taludes (extendiéndose y/o fluyendo) de volúmenes compuestos por rocas naturales, suelos, rellenos artificiales o combinaciones de estos materiales.

El movimiento de caídas de rocas, deslizamientos de terrenos, dispersiones de suelos y la mayoría de los flujos son perceptibles para el ojo humano por la rapidez de su ocurrencia mientras que la fluencia y la solifluxión ocurren tan lentamente que no pueden detectarse (Cruden y Varnes, 1996).

A continuación, se describen los distintos tipos de mecanismo del deslizamiento dependientes de la geometría de la superficie de desprendimiento y del grado en que el material deslizante permanece coherente (Dikau et al., 1996):

a) Traslacional: si el volumen rocoso desprendido de una pendiente se desliza a lo largo de una superficie relativamente plana (Figura 4). Las superficies relativamente comunes que facilitan el desprendimiento de los volúmenes deslizantes son diaclasas o planos de estratificación. El material puede convertirse progresivamente en un flujo de tierra, al extremo que en la región distal del pie tiende a licuarse.

b) Rotacional: cuando un volumen rocoso coherente se libera de una pendiente movilizándose sobre una superficie de deslizamiento curva cóncava hacia arriba produce una rotación según un eje subhorizontal contraria a la dirección del desplazamiento (Figura 4). A medida que el volumen se mueve cuesta abajo, la porción proximal a la cabecera se particiona en bloques que giran con una rotación alrededor de un eje perpendicular a la dirección general de la pendiente. Así, los bloques se basculan hacia la escarpa de la cabecera que forma, a menudo, un acantilado o corona con diseño cóncavo en forma de media luna (Figura 4). El movimiento de rotación hace que la superficie original del deslizamiento se particione en escalones basculados opuestamente a la tendencia general progresivamente menos empinada de la pendiente. Este patrón de bloques girados hacia atrás que forman depresiones que pueden acumular agua para crear estanques o áreas pantanosas y, a menudo, permanecen conservándose relativamente intactos, especialmente en la parte superior. Esta adición de agua y la pérdida de la cohesión de los materiales involucrados en el extremo distal del pie puede transformarse en un flujo de tierra. El movimiento descendente del volumen deslizante exhibe como resultado una deformación interna de la continuidad estructural que en su extremo distal se caracteriza por una relativa resurgencia. En este extremo se produce una mayor abundancia de fracturación con características dilatantes y pliegues subordinados cuyos ejes se disponen perpendicularmente a la dirección de transporte (Figura 4). 


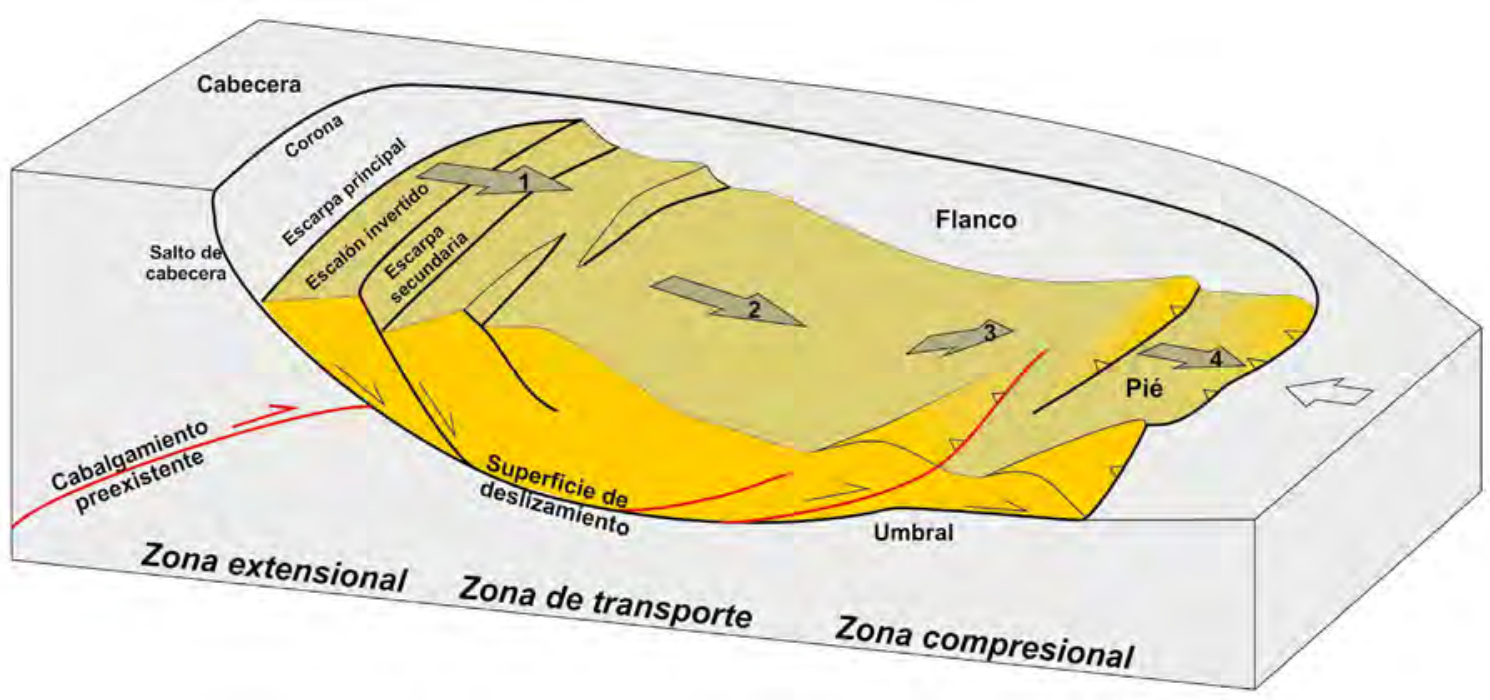

Figura 4. Esquema clásico de un deslizamiento gravitatorio rotacional, donde se aprecian las distintas zonas con expresiones morfoestructurales diferentes desde su cabecera hasta el pie distribuidos sobre la superficie de despegue cóncava. 1: sector extensional con bloques basculados contra la pendiente. 2: sector de transporte pendiente abajo. 3: sector de resurgencia. 4: sector de colapso. Se incluye el desplazamiento de un cabalgamiento preexistente (línea en rojo).

Los modelos analógicos permiten reproducir la distribución interna de los movimientos (por ejemplo: Ng y Chew, 2019) y comprender las consecuencias morfoestructurales que exhiben los materiales involucrados en los distintos sectores del desplazamiento gravitatorio (Figura 5).

Los límites laterales del deslizamiento completan el diseño en cubeta de geometría cóncava de la superficie infrayacente. En el extremo distal del pie del deslizamiento estos flancos tienden a converger en un cuello donde se genera un contexto más constrictivo con crestas transversales, surcos de replegamiento (hummocky), grietas transversales y radiales. Como consecuencia de trasponer este angostamiento horizontal y superar el umbral basal de la superficie de despegue el volumen deslizante pierde coherencia y colapsa haciéndose más erosionable por la adquisición de mayores disturbios internos y consecuente pérdida de cohesión (Figura 6).

De un modo más amplio, los mecanismos básicos de los deslizamientos pueden resumirse en las siguientes etapas: concentración de esfuerzos, tracción, arranque, movilización, vuelco rotacional, fluencia y colapso estructural. En general, se distinguen las siguientes dos fases principales en el desarrollo de los deslizamientos gravitatorios (Varnes, 1958, 1978; Hungr et al., 2013): a) Fase de previa a la rotura (o de preparación): puede ser de larga duración y donde se producen pequeñas deformaciones, a menudo imperceptibles, que pueden superar el orden métrico en los grandes deslizamientos. La superficie de separación entre la masa en movimiento y el terreno estable no ha llegado a desarrollarse por completo, pero las fracturas que comienzan a insinuarse facilitándose la percolación de aguas que provoca una disminución de la resistencia a movilizarse. El sistema comienza a concentrar, en lo que luego será su corona o escarpa, una zona de discontinuidad a lo largo de una superficie limitada entre el volumen suprayacente que se deslizará y el que permanecerá estable.

b) Fase de rotura (deslizamiento propiamente dicho): es por lo general muy rápida y caracterizada por la definición de una superficie de despegue que evoluciona de modo continuo desde un movimiento muy lento a extremadamente rápidos de modo progresivo, hasta que se produce el desplazamiento del volumen suprayacente y su posterior detención (Figura 4). El análisis una vez que tiene lugar la rotura y el reajuste del terreno deslizado es cinemático en el que deben tenerse en cuenta las características del recorrido, la reducción de las propiedades resistentes de la masa deslizada (condiciones de resistencia residual), la presencia de agua y de obstáculos. 

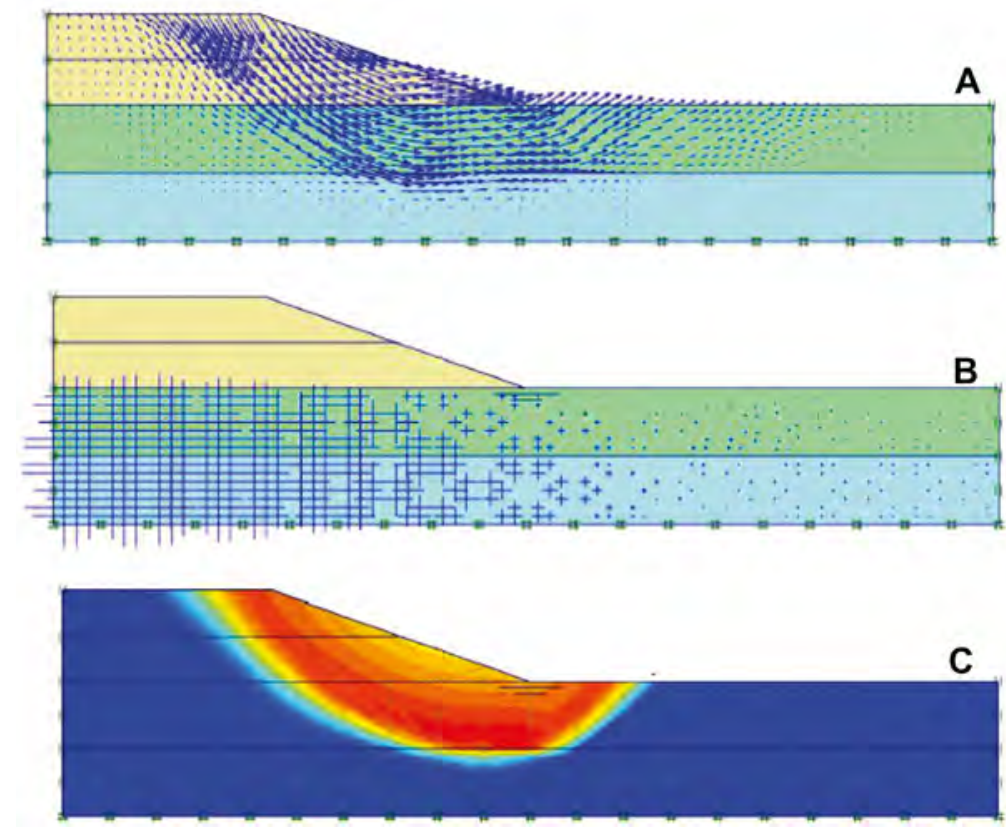

Figura 5. Esquemas simplificados de ejemplos de la distribución interna de los desplazamientos gravitatorios y su basamento indeformado a partir de modelos digitales analógicos (modificado de $\mathrm{Ng}$ y Chew, 2019).

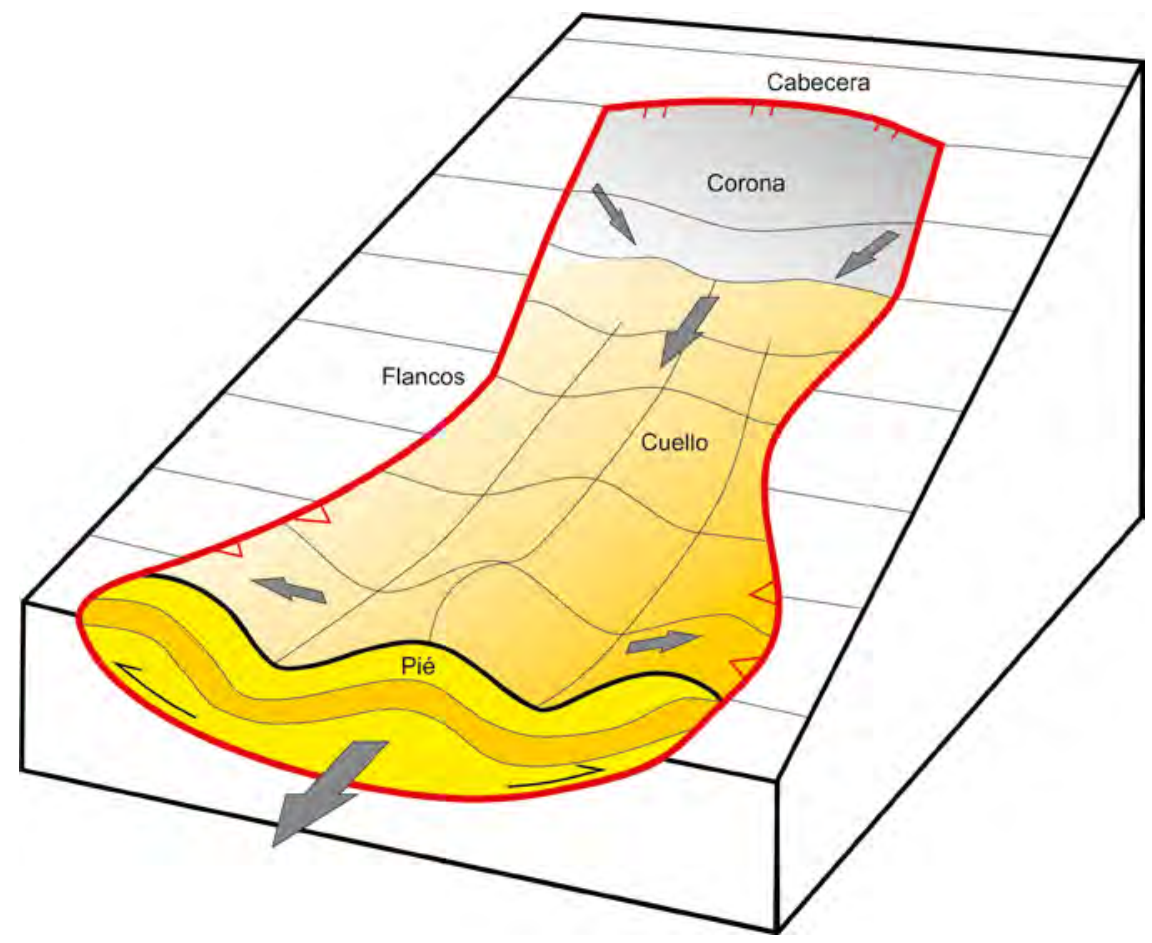

Figura 6. Esquema 3D de la geometría localmente compresional del pie del deslizamiento debido a la geometría cóncava en forma de cubeta de la superficie de despegue. 
Entre las causas que determinan y disparan los deslizamientos gravitatorios se encuentran los movimientos sísmicos, la absorción excesiva de agua, congelamiento y derretimiento, socavamiento en su base, y carga de la pendiente (Dikau et al., 1996; Hansen, 2000). Frecuentemente, los deslizamientos se forman debido a la eliminación de una base de pendiente, ya sea de procesos naturales o artificiales (Crozier, 1986). La erosión de las corrientes o las olas, así como la construcción de carreteras, son instigadores comunes para el desencadenamiento de los deslizamientos gravitatorios al eliminarse el soporte físico de la pendiente (Dikau et al., 1996).

La humectación profunda es una causa común, lo que explica por qué los deslizamientos frecuentemente se asocian con periodos de fuertes lluvias, tormentas y flujos de tierra (Hutchinson y Bhandari, 1971; Gostelow, 1991; Yan et al., 2019). El agua precipitada proporciona una lubricación y pérdida de cohesión interna por la presión de poros que se genera y facilita su deslizamiento por el aumento la masa propia del material. Ambos factores aumentan la tasa de caída. Como ejemplo de deslizamientos masivos producidos por terremotos el de Turnagain Heights en Anchorage (Alaska) fue desencadenado por un terremoto de magnitud 8.4 que resultó en la licuefacción del suelo y alrededor de 75 casas fueron destruidas (Seed y Wilson, 1967).

En ocasiones, deformaciones de apenas unos centímetros en grietas de tracción que separan un bloque rocoso de un acantilado, son suficientes para localizar y generar la discontinuidad que dispara el deslizamiento. Sin embargo, en grandes deslizamientos, deformaciones de varios metros pueden ser insuficientes para generar una superficie de corte que afecte al conjunto del volumen rocoso inestable (rotura progresiva).

Las reactivaciones pueden mostrar cambios en relación con la fase de rotura después de periodos prolongados de inactividad donde las propiedades de los materiales deslizados pueden haber cambiado, entre otros mecanismos, por efecto de la consolidación, drenaje o alteración. En ocasiones, se dan fases de reactivación en las que el movimiento se reproduce aprovechando las superficies de rotura generadas previamente (Leroueil et al., 1996). Estas reactivaciones pueden ser episódicas o continuas con variaciones estacionales de la velocidad de deformación en función de la intensidad de los factores desencadenantes que pueden ser provocados por sismicidad y/o temporadas de altas precipitaciones.
También, los deslizamientos pueden ocurrir bajo el agua a lo largo de los márgenes de los continentes e islas, como resultado de la acción de las mareas o un gran evento sísmico que pueden generar tsunamis desastrosos. Uno de los deslizamientos más grandes conocidos ocurrió en el Plioceno, o mas recientemente, en el extremo sureste del Banco Agulhas (al sur de África) tiene $750 \mathrm{~km}$ de largo, $106 \mathrm{~km}$ de ancho y tiene un volumen de $20,000 \mathrm{~km}^{3}$ de material movilizado. Es un gran desplazamiento compuestos de masas de sedimentos alóctonos proximales y distales separadas por una gran cicatriz cóncava en su cabecera (Dingle, 1977; Uenzelmann-Neben y Huhn, 2009). Estos fenómenos subacuáticos han sido frecuentemente reconocidos a partir de conspicuas estratificaciones convolutas sinsedimentarias en ambientes marinos fósiles sometidos a inestabilidades como ocurre en el Mar Muerto (Alsop et al., 2017).

La velocidad de caída varía ampliamente, desde metros por segundo hasta pocos metros por año condicionada, fundamentalmente, por la naturaleza de los materiales involucrados y las pendientes topográficas (Alsop et al., 2017). Los casos de deslizamientos repentinos generalmente ocurren después de terremotos o fuertes lluvias continuas, y pueden estabilizarse en unas pocas horas, aunque la mayoría de las veces se desarrollan durante períodos relativamente más largos, que tardan meses o años en alcanzar la estabilidad (Figura 7).

Ejemplos de deslizamiento gravitatorios lentos son el Swift Creek, que consiste en un deslizamiento rotacional profundamente asentado ubicado en la montaña Sumas (estado de Washington en Estados Unidos) y el deslizamiento de Man Tor (Escocia) que se desarrolla con una pendiente de $20^{\circ}$ a lo largo de un kilómetro con una velocidad promedio de unos $12 \mathrm{~cm} /$ año (Waltham y Dixon, 2000).

A partir de la interpretación de la relación del relieve topográfico de la superficie del volumen deslizado y la magnitud del desplazamiento sobre la superficie de despegue se puede estimar que cuando mayor es la traslación el relieve tiende a disminuir. Esto podría deberse por el más intenso disturbio interno del volumen del deslizamiento al pasar por el umbral de la superficie de despegue que favorece un disturbio interno que lo hace menos competente (Terzaghi y Peck, 1967) y, por lo tanto, son más proclives al colapso y erosión. 


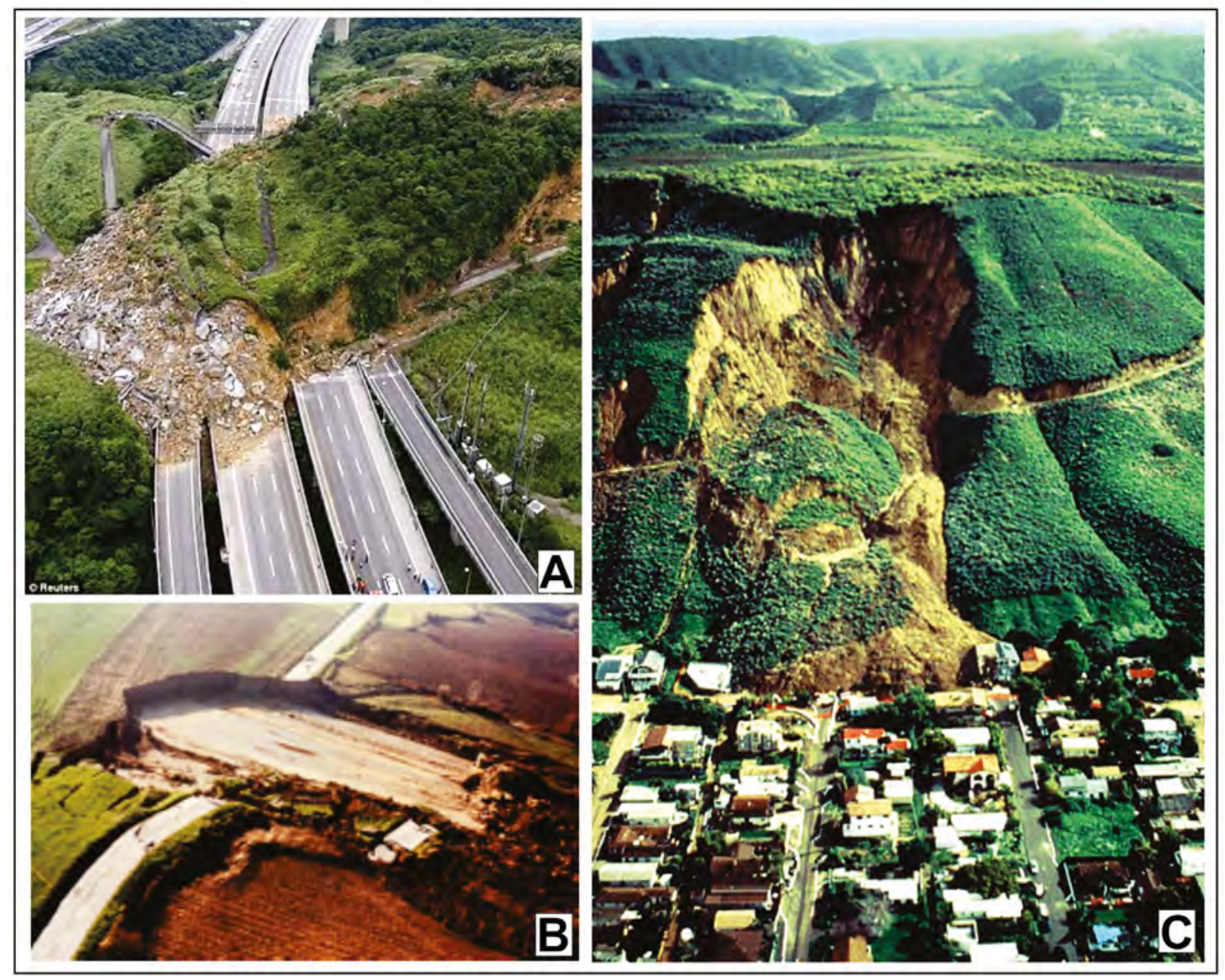

Figura 7. Ejemplos clásicos de deslizamientos gravitatorios rápidos. A. Sobre una autopista de Taiwán. B. Deslizamiento La Conchita, California del 4 de marzo del 1995 (tomados de Girty, 2009). C. Deslizamiento traslacional controlado por un plano de estratificación pre-existente de Murazzano, Italia (tomado de Hungr et al., 2013).

\section{Metodología}

Con la finalidad de conceptualizar las principales características de los procesos de deslizamiento gravitatorio se realizó una recopilación de aspectos teóricos de sus morfologías y procesos generadores con menciones de casos reales clásicos extraídos de la bibliografía especifica.

Para la descripción e interpretación del deslizamiento gravitatorio de Guando se realizó una síntesis de la evolución tectónica del sector y se integró de modo 3D (Hennings et al., 2000) la información de subsuelo disponible con la cartografía topográfica y geológica de superficie.
Para la facilitar la interpretación geomorfológica de la topografía del sector se realizaron capturas de modelos digitales de elevación de alta precisión (con pixelado 3601 x 3601 de resolución espacial 1 arc-second) provenientes del programa abierto de imágenes satelitales SRTM (Shuttle Radar Topography Mission) superpuestas sobre cartografías geológicas regionales. Debido a las excelentes evidencias que ofrece la cartografía digital se obtuvieron visualizaciones de bloques diagramas y perfiles con distintas orientaciones resaltadas con sombreados artificiales que facilitan la interpretación geomorfológica (Hergarten et al., 2014).

Se hace una breve reseña de la historia geológica de la Cuenca del Valle Superior del Magdalena con la 
finalidad de analizar los efectos del deslizamiento gravitatorio de Guando en la interpretación estructural convencional del yacimiento petrolero localizado en su subsuelo. Para describir la geometría de la superficie de deslizamiento y estimar su evolución, se confeccionaron modelos 4D apoyados por transectas ajustadas con información sísmica de reflexión disponible previamente estudiados por Rossello y Saavedra (2016).

\section{Resultados}

Los objetivos petroleros del Campo Guando se ubican en el extremo nor-oriental de la Sub-Cuenca Girardot dentro de la porción septentrional de la Cuenca del Valle Superior del Magdalena (Mojica y Franco, 1990; Rincón et al., 2003; Barrero et al., 2007) en gran parte debajo del deslizamiento gravitatorio homónimo (Figura 8). La zona dentro de la cual se encuentra, sobre el flanco occidental de la Cordillera Oriental de Colombia, está considerada con una alta amenaza de riesgo por remoción en masa en función de las características topográficas y climáticas dominantes (Arévalo-Chaves y Parias-Villalba, 2013).

Desde el punto de vista del análisis tectónico regional, el Valle Superior del Magdalena (VSM) es una típica cuenca rampa (Cobbold et al., 1993) que presenta una historia multiepisódica acotada fundamentalmente a las distintas fases de la tectónica Andina y está limitado por el occidente con la Cordillera Central y por el oriente con la cordillera Oriental por fallamientos cabalgantes con vergencia opuesta, como el sistema de fallas de Magdalena (Schamel, 1991; Cooper et al., 1995; Toro et al., 2004).

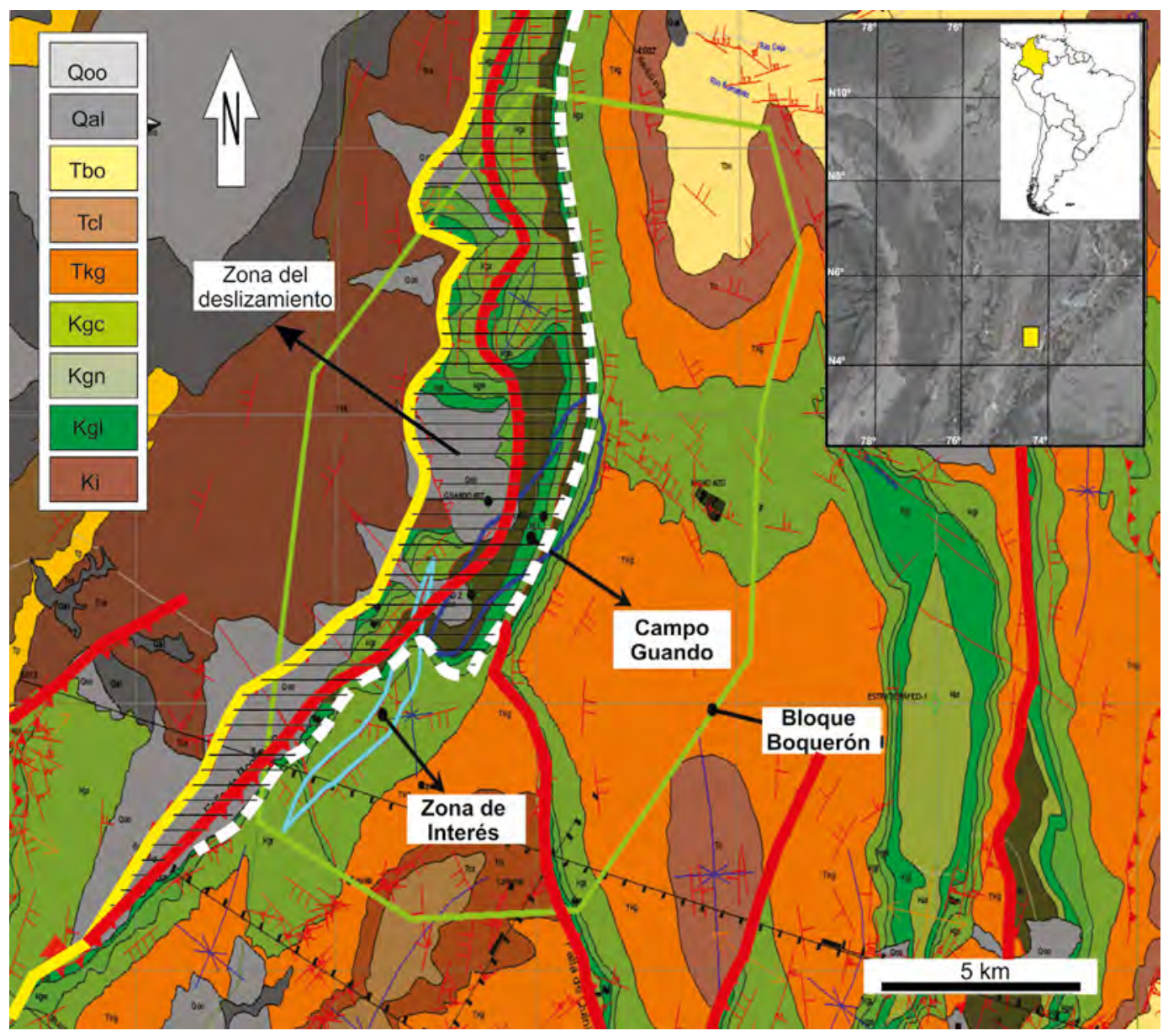

Figura 8. Localización del campo Guando en el VSM sobre un mapa geológico regional. Zona con rayado horizontal indica afloramientos disturbados por el deslizamiento gravitatorio a partir de la cabecera (línea punteada blanca) y el límite occidental (Línea amarilla). La línea roja indica el afloramiento de los cabalgamientos (tomado de Rossello y Saavedra, 2016). Ki: Formación Yavi; Kgl: F: Formación Caballos, Kgn: Grupo Villeta, Kgc: Formación Monserrate, Tkg: Formación Guadala, Tcl: F. Barzalosa, Tbo: F. Orteguaza, Qal: Depósitos aluviales, Qoo: Sedimentos actuales (Cossio et al., 1995). 
A continuación, se resumen los principales estadios tectónicos que afectaron la región basados en los datos de superficie y subsuelo e interpretaciones propias y recopiladas de la abundante bibliografía relacionada (e.g. Mojica y Franco, 1990; Gómez et al., 2003; Sarmiento y Rangel, 2004; Montes et al., 2005; Sarmiento-Rojas et al., 2006; Mora et al., 2010). Si bien la historia tectónica de la cuenca VSM comenzó en el Triásico-Jurásico como un depocentro de retroarco que pudo haber sido controlado, al menos parcialmente, por anisotropías preexistentes Paleozoicas (De Freitas, 2001). Sin embargo, la conformación tectónica actual la adquiere a partir del Terciario tardío hasta el presente, con el depósito de sedimentaciones sintectónicas en cuencas intermontanas.

Las siguientes tres fases Andinas debidas a la convergencia de la placa de Nazca con la placa de Sudamericana son las principales responsables de los rasgos estructurales que se expresan en la información sísmica y se asocian con el desarrollo de los sistemas petroleros de varios campos de la región (De Freitas et al., 2006; Jaimes y De Freitas, 2006, entre otros).

Fase Peruana o "Evento Mochica": en general, poco reconocido en Colombia a pesar de estar muy bien representado en el resto de los Andes (Cobbold et al., 2007), en el VSM se acota al Albiano-Cenomaniano con una dirección principal de compresión WSW-ENE (Jaimes y De Freitas, 2006).

Fase Incaica: con su clímax durante el Eoceno Medio (e.g. Schamel, 1991; Cooper et al., 1995; Cobbold et al., 2007) comenzó con un incremento de la velocidad de convergencia determinantes de estructuras de acortamiento cortical expresadas por cabalgamientos ampliamente distribuidos que involucran al basamento, especialmente en los márgenes occidental y oriental de la Cordillera Central.

Fase Quechua: con varios episodios deformativos durante el Neógeno se asocia principalmente con la deformacióny los mayores levantamientos dela Cordillera Oriental produciéndose nuevos cabalgamientos y la posterior depositación de los sedimentos continentales. Durante esta fase se produce el principal funcionamiento del cabalgamiento Boquerón (entre otros) asociado sintectónicamente con pliegues con ejes dispuestos en direcciones preferencialmente perpendiculares a la dirección principal de convergencia WSW-ENE (Jaimes y De Freitas, 2006).

Como consecuencia de la tectónica compresional que exhibe en la región estudiada se desarrolla el cabalgamiento Boquerón que representa el principal rasgo tectónico del campo Guando (Schamel, 1991; Cooper et al., 1995; Sarmiento y Rangel, 2004). De esta manera, los modelos estructurales propuestos consideran al cabalgamiento Boquerón con una inclinación regional de unos $30^{\circ}$ hacia el este y con vergencia al oeste como la principal estructura que superpone una escama que sepulta y sella a las unidades productivas que determinan sus principales objetivos en su bloque yacente (Rincón et al., 2003). Interpretaciones previas consideraban al cabalgamiento Boquerón con su superficie de despegue exhibiendo sobre los extremos occidentales, disposiciones espaciales locales con inclinaciones que cambiaban notablemente con respecto a la tendencia regional. Así, las superficies llegaban al punto de mostrar una la inclinación invertida hacia el occidente, o incluso. exhibirse con pandeos cóncavos típicamente lístricos hacia arriba (Figura 9).

Los diseños curvados con inclinaciones opuestas en el extremo occidental con respecto a la tendencia espacial regional interpretada en su continuidad oriental resultaban reñidos con los fundamentos mecánicos de la interpretación estructural 4D. Esto debido a que no cumple con la Ley de Anderson que establece una relación angular determinada que deben guardar la orientación del campo de esfuerzos generador con las superficies de fallamientos producidas (Ramsay y Huber, 1983; Price y Cosgrove, 1990; Rossello, 2001, entre otros).

Esta relación determina que el esfuerzo principal máximo $\sigma_{1}$ y las superficies de fallamientos siempre van a mantener un ángulo menor a $45^{\circ}$, frecuentemente del orden de $30-40^{\circ}$. Por lo tanto, independientemente que se trate de un fallamiento normal, inverso o transcurrente, siempre el esfuerzo principal máximo $\sigma_{1}$ se dispone invariablemente con un ángulo menor de $45^{\circ}$ (cercano a $30-40^{\circ}$ ) con respecto al plano de fallamiento sobre el cual actúa (Figura 10).

Si se considera al cabalgamiento Boquerón como respuesta a un acortamiento tectónico compresional subhorizontal y una vergencia occidental del bloque colgante, se debe aceptar como su responsable a un esfuerzo principal máximo horizontal. De este modo, el ángulo de inclinación debe ser menos de $45^{\circ}$ hacia el oriente, tal como se lo interpreta regionalmente. Por ello, en el caso de considerar al extremo occidental del cabalgamiento Boquerón con una inclinación oriental debería tener un funcionamiento normal o extensional o bien tener una vergencia contraria a la regional. 

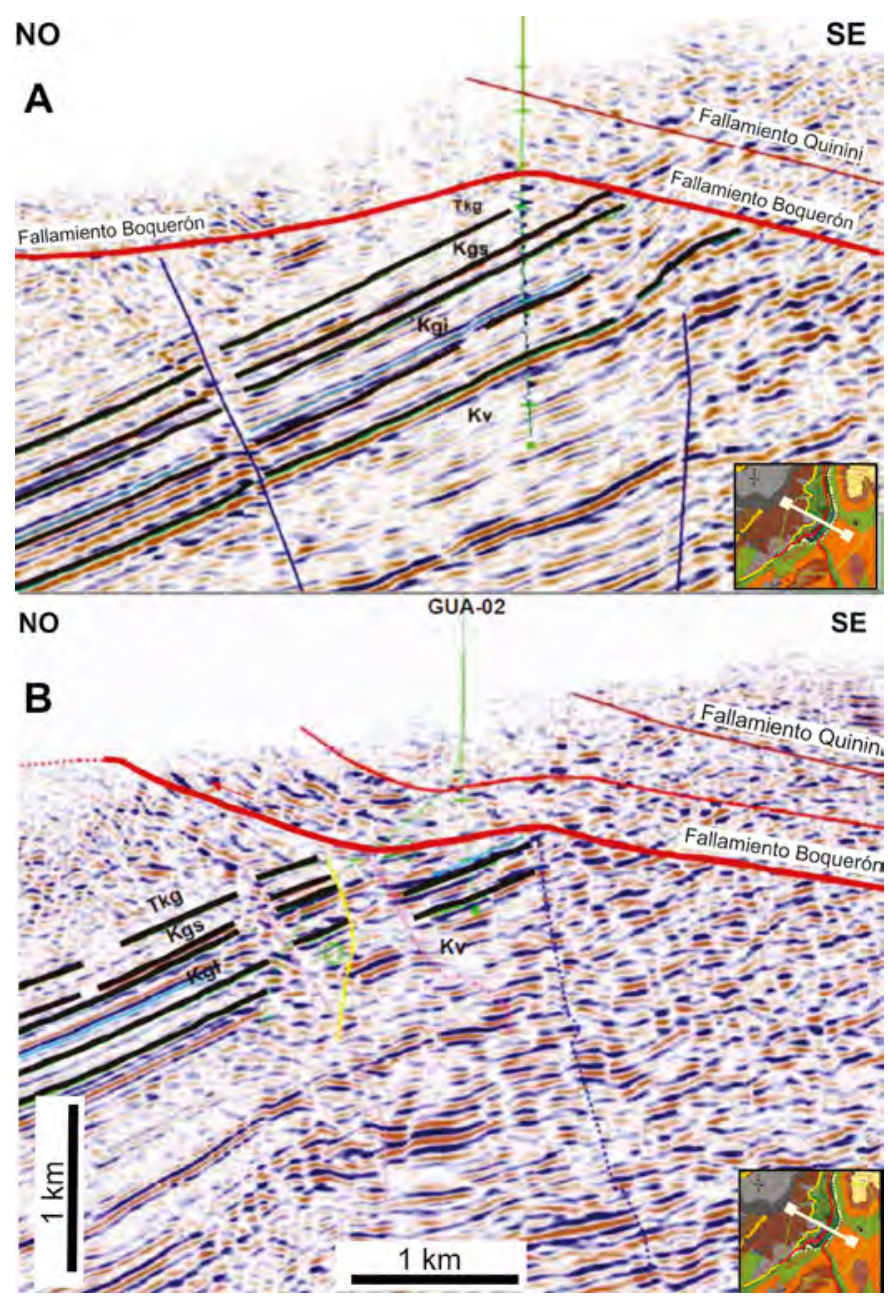

Figura 9. Ejemplos de interpretaciones anteriores al presente trabajo. A y B. Líneas sísmicas 2D (PSTM), con las trazas sintéticas de pozos productores en niveles reservorios (areniscas del Guadalupe $\mathrm{Kg}$ ) que inclinan hacia el noroeste localizados en el bloque bajo del Cabalgamiento Boquerón (tomado de Rincón et al., 2003; Rossello y Saavedra, 2016). Véase localización en la Figura 8.

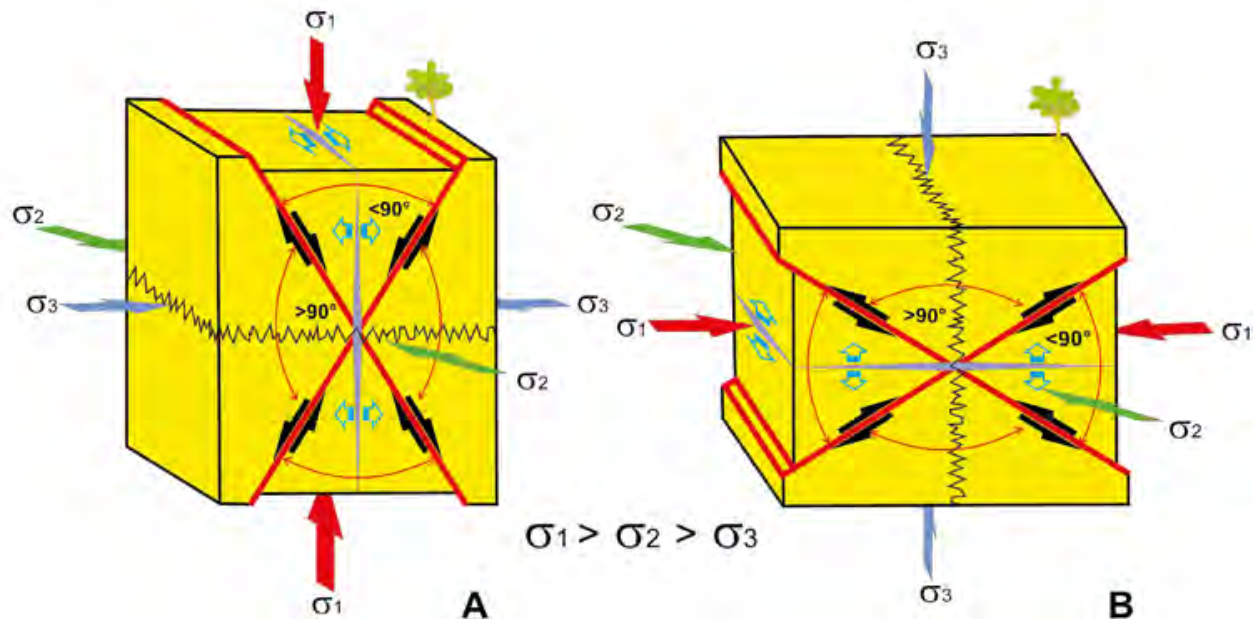

Figura 10. Esquemas de la Ley de Anderson que establece relaciones espaciales unívocas entre el campo de esfuerzos y las fracturas (fallas y diaclasas) desarrolladas. A. Extensión de la superficie terrestre (en rojo fallas normales). B. Compresión de la superficie terrestre (en rojo fallas inversas). 
Con la finalidad de interpretar el modelo estructural del campo Guando, Rossello y Saavedra (2016) realizaron un estudio de la información geológica disponible, con especial énfasis en el análisis de la expresión superficial del campo Guando apoyada por imágenes RADAR y un relevamiento topográfico digital y a partir de la reinterpretación de un relevamiento sísmico 3D y controles de pozos. De esta manera, se reconoció el fenómeno de deslizamiento gravitatorio moderno de Guando que modifica notablemente el modelo estructural previamente conocido de un fallamiento de bajo ángulo que sobreimpone niveles del Grupo Villeta sobre niveles más jóvenes.

El volumen rocoso afectado por el deslizamiento de Guando tiene sobre el campo petrolero una llamativa expresión de suaves relieves que se disponen al pie de la entrante hacia el Este bien marcada que exhibe la pendiente abrupta del filo topográfico principal, determinante de la actual divisoria de aguas, dispuesta submeridianalmente entre Melgar e Icononzo (Figura 11).
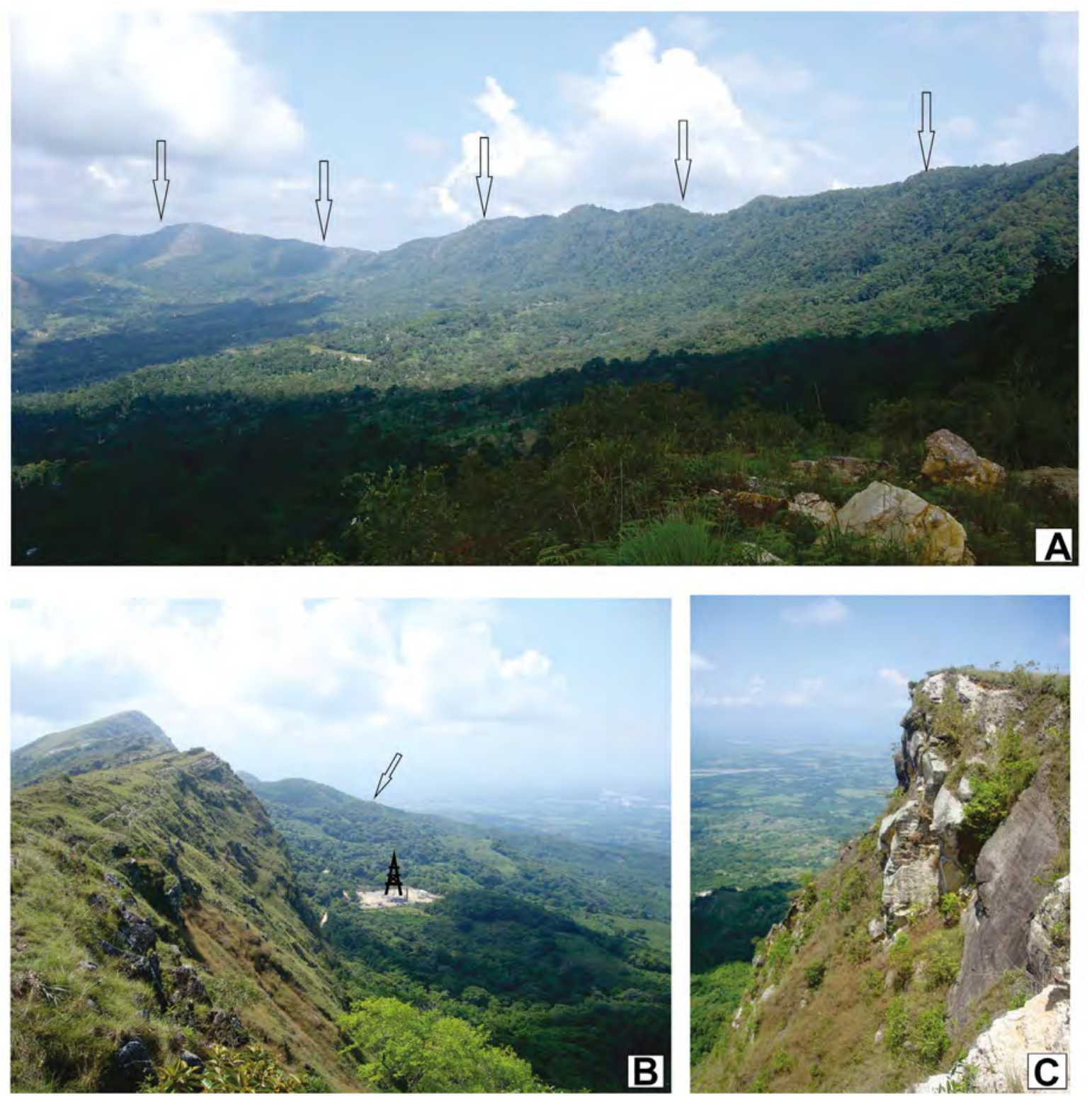

Figura 11. Fotografías. A. Vista hacia el noreste donde se aprecia el filo topográfico que marca el límite oriental del campo Guando. B. Vista hacia el Sur donde se aprecia en primer plano la fuerte pendiente de la escarpa y la posición de un pozo sobre un bloque del deslizamiento. C. Vista hacia el Norte de la escarpa constituida por areniscas de la Formación Guadalupe. 
A partir de la interpretación topográfica digital de diferentes vistas de modelos de elevación de alta precisión con pixelado 3601 x 3601 de resolución espacial 1 arc-second (provenientes del programa abierto de imágenes satelitales SRTM Shuttle Radar Topography Mission), es posible reconocer geomorfológicamente el desarrollo del deslizamiento de Guando que se extiende desde su cabecera al pie del filo montañoso entre Icononzo y Melgar, hasta esta última localidad donde puede reconocerse la posición más distal del pie (Figura 12).

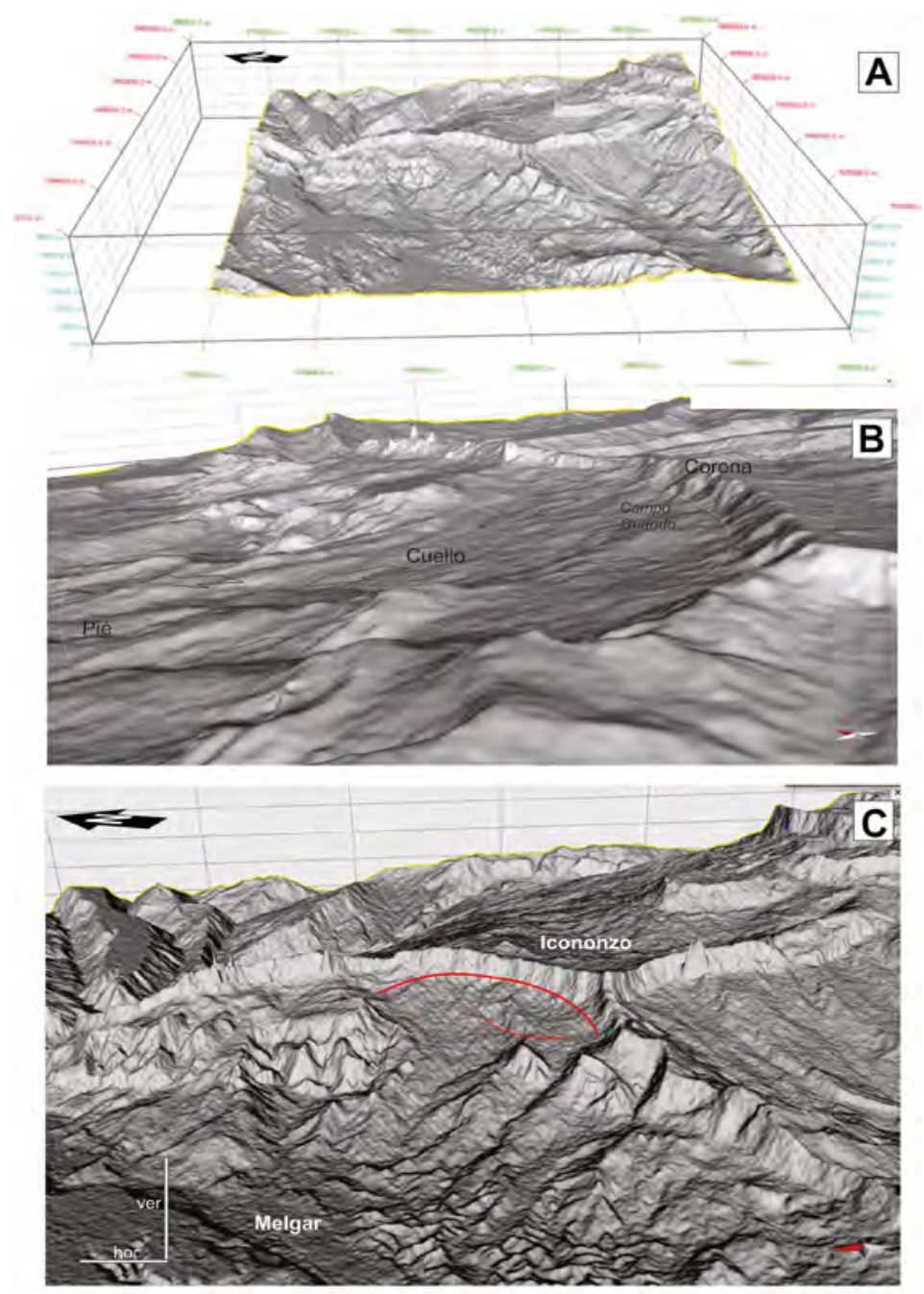

Figura 12. Esquemas topográficos del deslizamiento de Guando a partir de modelos digitales de imágenes satelitales SRTM con una definición de 12,5 m de pixel. A. Vista 3D hacia el Este. B. Vista rasante hacia el Norte. C. Vista más cercana hacia el Este con indicación del sector ocupado por el deslizamiento.

Desde el punto de vista de la interpretación del subsuelo mediante la información sísmica disponible, el deslizamiento Guando constituye un volumen sedimentario dispuesto por encima de las secuencias indisturbadas de los objetivos productores (Grupos Guadanlay, Guaduas y Guadalupe). Este deslizamiento presenta una superficie basal de despegue con diseño de cubeta lístrica en perfil y aspecto de una medialuna cóncava en planta que se une hacia el oriente con la escarpa del filo topográfico (Figura 13).
Los datos de registros de imágenes de pozos con indicación de la disposición espacial de discontinuidades (Serra, 2008) corroboran que por encima del plano del cabalgamiento Boquerón, se encuentran rasgos planares atribuidos a fracturamientos con ángulos y direcciones aleatorias que no exhiben un patrón característico. El mismo comportamiento lo muestran los límites estratigráficos donde los azimuts y buzamientos son caóticos (Figura 13A). Por esta razón, la caracterización geométrica y temporal 
de la morfología de la superficie de despegue del deslizamiento Guando resulta fundamental para el diseño de las actividades exploratorias, localización de instalaciones de facilidades logísticas y la orientación de los sondeos productivos.
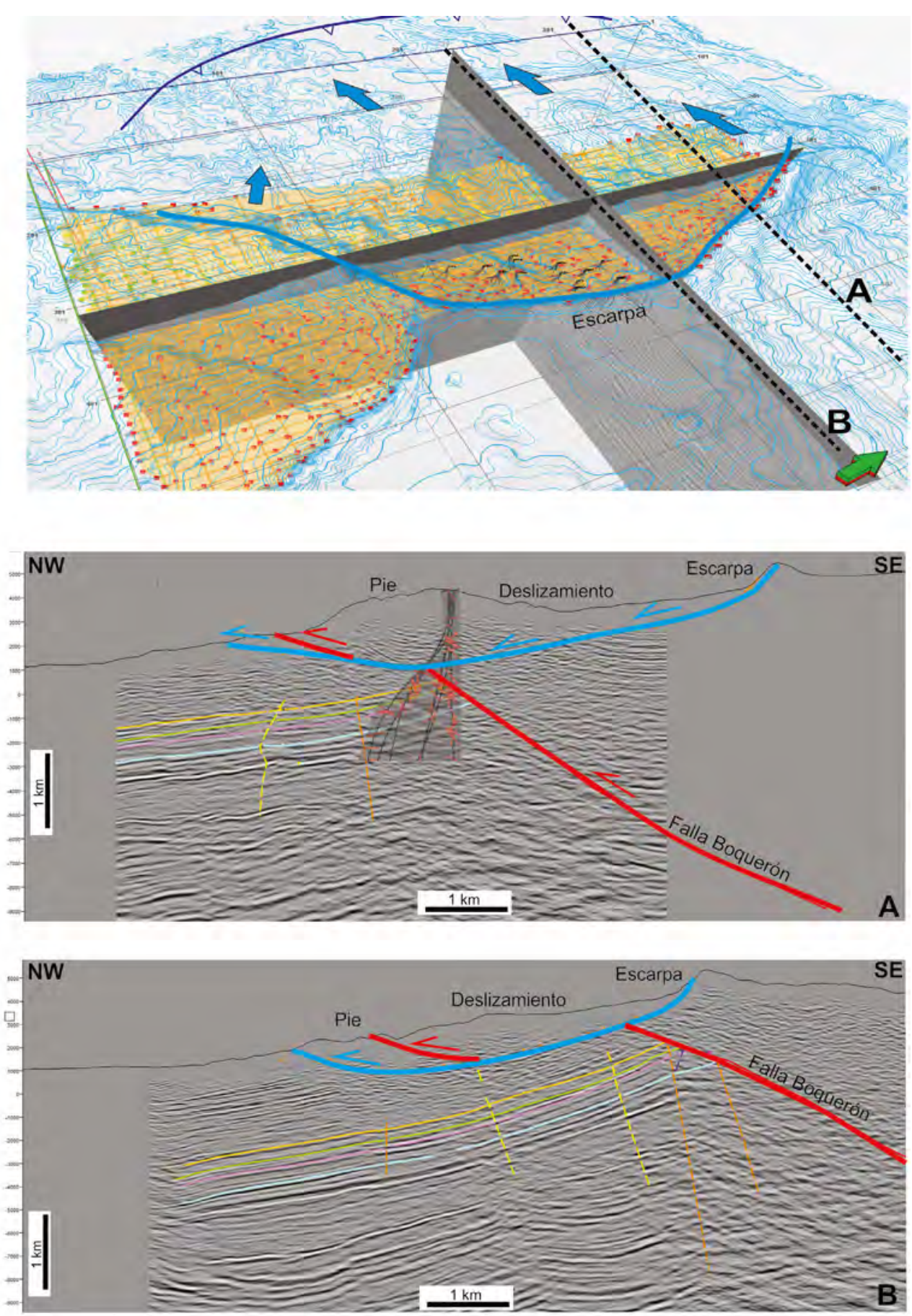

Figura 13. Vista proyectada 3D donde se aprecia la geometría lístrica de los rasgos morfoestructurales de la superficie basal del deslizamiento. A y B. Transectas interpretativas del cabalgamiento Boquerón parcialmente disectado y trasladado hacia el NW por la superficie del deslizamiento (tomado de Rossello y Saavedra 2016). 


\section{Discusión}

El desencadenamiento del proceso deslizante gravitatorio de Guando pudo haber sido favorecido por la interacción de los siguientes factores: i) la alta inestabilidad tectónica regional en medio de cordilleras andinas en pleno desarrollo y exhumación, ii) los procesos erosivos intensos debido al clima y cambios bruscos de nivel de base y iii) la naturaleza multicomposicional del macizo rocoso con niveles incompetentes intercalados (Grupo La Luna). De este modo, la geometría particular previamente interpretada del cabalgamiento Boquerón se debe a que su extremo occidental y más somero está modificado y desplazado por el plano de deslizamiento que en la información sísmica y los controles de pozos parece asociado a una misma superficie (Figura 14).

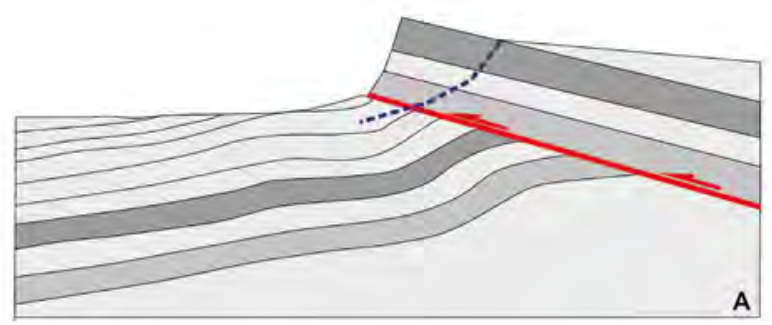

A

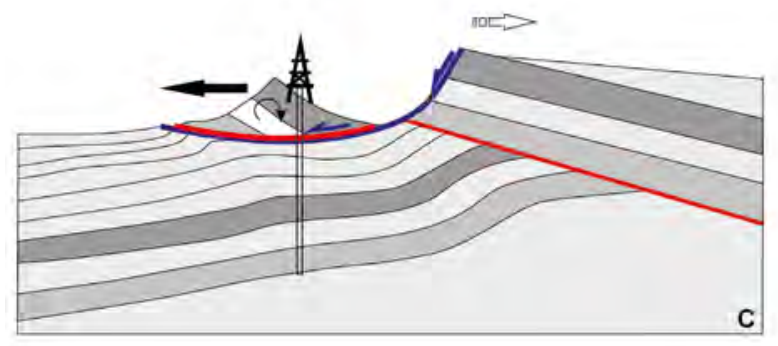

Las interpretaciones estructurales del campo Guando previas a este trabajo mostraban superficies del cabalgamiento Boquerón que cambiaban notablemente de inclinación hacia el Oeste y características morfológicas en el sector que actualmente está afectado por el deslizamiento gravitatorio, muy reñidas con los fundamentos mecánicos de la interpretación estructural 4D. Si se tiene en cuenta la acción de deslizamientos gravitatorios superpuestos a rasgos tectónicos característicos de la convergencia Andina, como son los cabalgamientos, se sugiere realizar importantes modificaciones en el modelo estructural para hacerlos compatibles con los datos estudiados. De este modo, se considera que el diseño previamente asumido del fallamiento Boquerón está fuertemente modificado por el deslizamiento gravitatorio que hace que la disposición inicial de su superficie se vea fuertemente obliterada.
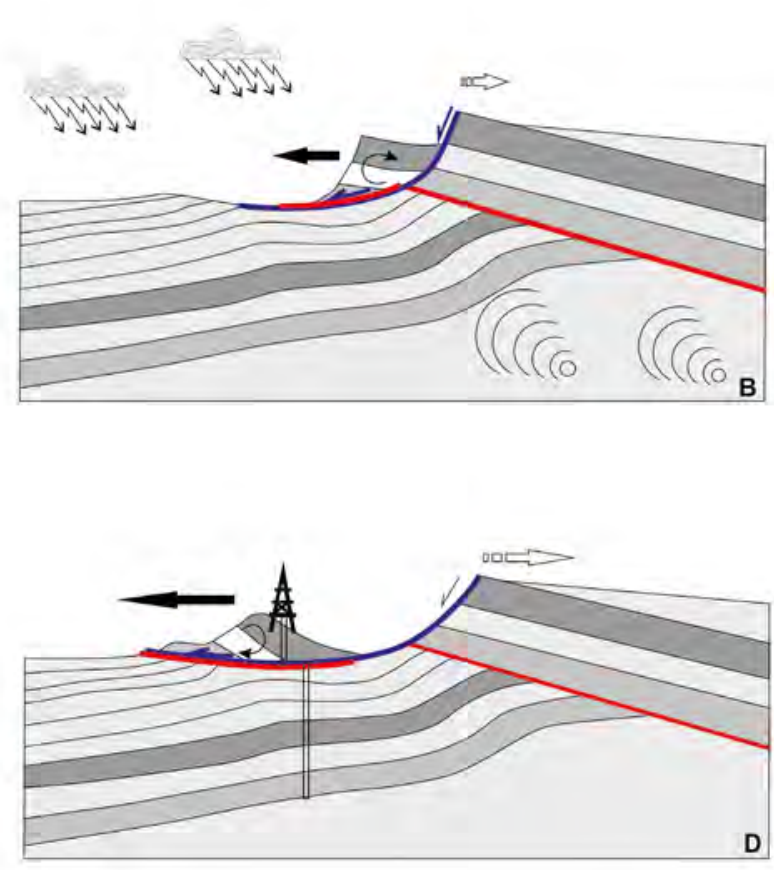

Figura 14. Esquemas evolutivos del deslizamiento gravitatorio que afecta al fallamiento Boquerón y su compartimiento deslizante colgante a partir de secciones conceptuales. A. Estado previo donde se indica la posición previa del plano de deslizamiento. B. Inicio del deslizamiento incitado por una sismicidad y climatología. C. Deslizamiento avanzado donde se localiza un pozo productor. D. Estado actual donde se aprecia la deformación del pozo productor.

La evolución de este deslizamiento gravitatorio se puede explicar como un rasgo reciente y todavía en evolución que afecta al fallamiento Boquerón, proporcionándole la particular geometría lístrica que previamente fue interpretada. Además, este deslizamiento gravitatorio desarrollado sobre el Campo
Guando puede explicar los problemas de colapsos de tuberías a partir de deformaciones tangenciales en profundidades compatibles con su localización y la presencia de hidrocarburos en reservorios someros y variablemente disturbados, los que debieron haberse cargado antes de su funcionamiento. Lamentablemente, 
aun no se dispone de algún cálculo de la velocidad del desplazamiento, el cual podría ser realizado a partir de diversas metodologías aplicadas en otros casos (Working Party for World Landslide Inventory, 1995; Tofani et al., 2013; Tiampo et al., 2013). En el caso de poseer información sobre la velocidad en la que se está movilizando, permitiría pronosticar y eventualmente ejecutar acciones para mitigar los efectos de los desplazamientos (Záruba y Mencl, 1969). De esta manera, podrían ser tenidos en cuenta en la localización de la infraestructura para estimar su vida útil y eventuales atenuamientos en el caso de los pozos que deberán atravesar la superficie basal del desplazamiento.

Las actuaciones para mitigar las consecuencias de los deslizamientos antes y después de la rotura son netamente distintas. En la fase previa se tiene que estimar la potencialidad de la inestabilidad dentro de su contexto geológico con vistas a determinar las medidas de protección y/o contención de la ladera. En el caso de rotura manifiesta, hay que adoptar medidas diversas que van desde la evacuación inmediata si ésta es necesaria y viable, hasta trabajos de contención y reacondicionamiento. Las técnicas y procedimientos que habrá que poner en obra serán específicos para cada una de las fases y requerirán aproximaciones diferenciadas. Las condiciones de estabilidad en la fase previa a la rotura se evalúan teniendo presente la geometría inicial de la ladera, el límite de resistencia de los materiales involucrados, las condiciones de agua subterránea y/o de percolación y el efecto de eventuales fuerzas externas (sismos, sobrecargas, excavaciones, etc.).

A partir de la interpretación de la relación del relieve topográfico de la superficie del volumen deslizado y la magnitud del desplazamiento sobre la superficie de despegue (Figura 12) se puede estimar que cuando mayor es la traslación el relieve disminuye en su altura. Esto podría deberse por el más intenso disturbio interno del volumen del deslizamiento al pasar por el umbral de la superficie de despegue que favorece un disturbio interno que lo hace menos competente (Terzaghi y Peck, 1967) y, por lo tanto, son más proclives al colapso y erosión.

\section{Conclusiones}

Los deslizamientos gravitatorios son frecuentes en regiones montañosas con relieves accidentados y donde son habituales la meteorización, la acción de sismicidad y condiciones climáticas húmedas como ocurre en el caso de Guando. La conformación multicomposicional con respuestas mecánicas disimiles de los volúmenes involucrados facilitan la determinación de superficies de despegues que aprovechan discontinuidades mecánicas para su desarrollo.

El estudio detallado de la información de superficie y subsuelo en el campo Guando permitió reconocer un fenómeno de deslizamiento gravitatorio moderno que modifica notablemente el modelo estructural de un fallamiento de bajo ángulo con diseños incompatibles con los campos de esfuerzos actuantes que sobreimpone niveles sobre otros más jóvenes. Este deslizamiento gravitatorio, de funcionamiento reciente y activo, determina un bloque colgante deslizante hacia el $\mathrm{W}$ dispuesto por encima de las secuencias indisturbadas de los objetivos petroleros.

El desencadenamiento del proceso deslizante gravitatorio pudo haber sido favorecido por un relieve pronunciado y la interacción de: i) la alta inestabilidad tectónica regional en medio de cordilleras andinas en pleno desarrollo y exhumación, ii) los procesos de meteorización y erosión intensos debido al clima y cambios bruscos de nivel de base y iii) la naturaleza multicomposicional del macizo rocoso con niveles incompetentes intercalados.

Este nuevo modelo estructural permite extraer observaciones novedosas que tienen en cuenta las características integrales del cabalgamiento Boquerón y los últimos acontecimientos deformativos debidos al deslizamiento Guando que permite encontrar explicaciones coherentes con la geometría que surge de las interpretaciones estructurales y los problemas mecánicos de algunos de los pozos productores e inyectores. La diversidad espacial y temporal de las estructuras detectadas en el Campo Guando obstaculiza, por lo tanto, la aplicación de técnicas de reconstrucción geométricas que consideran todos los eventos en un mismo proceso y obliga, en consecuencia, a un análisis tectónico multiescalar y evolutivo.

Finalmente, se concluye que el modelo estructural del campo Guando presenta particularidades tectónicas muy importantes debidas a la presencia del desplazamiento gravitatorio que si es adecuadamente monitoreado puede contribuir con el mejor manejo de su exploración y explotación y prevenir riesgos catastróficos a las instalaciones cercanas. 


\section{Agradecimientos}

Se desea dejar constancia de nuestro agradecimiento al Ing. Juan Badillo por su asistencia en la preparación de las cartografías digitales. Las correcciones y sugerencias realizadas por el arbitraje del Dr. Ferran Colombo Piñol y de otro anónimo contribuyeron con mejorar la calidad y comprensión del trabajo.

\section{Referencias}

Alcántara-Ayala, I. (2000). Landslides: ¿deslizamientos o movimientos del terreno? Definición, clasificaciones y terminología. Investigaciones Geográficas, 41, 7-25. https://doi.org/10.14350/ rig.59101

Alcántara-Ayala, I.; Echavarría-Luna, A.; GutiérrezMartínez, C.; Domínguez-Morales, L.; NoriegaRioja, I. (2014). Inestabilidad de laderas. Centro Nacional de Prevención de Desastres (México), Serie Fascículos (2da. Versión electrónica), 39 pp.

Alsop, G.I.; Marco, S.; Weinberger, R.; Levi, T. (2017). Upslope-verging back thrusts developed during downslope-directed slumping of mass transport deposits. Journal of Structural Geology, 100, 4561. https://doi.org/10.1016/j.jsg.2017.05.006

Arévalo-Chaves, D.A.; Parias-Villalba, J.P. (2013). Análisis de amenaza por fenómenos de remoción en masa en la región del Boquerón ubicada entre los departamentos de Cundinamarca y Tolima mediante el uso de un Sistema de información geográfica de libre distribución. Tesis, Universidad Católica de Colombia, Bogotá, Colombia.

Barrero, D.; Pardo, A.; Vargas, C.A.; Martínez, J.F. (2007). Colombian sedimentary basins: nomenclature, boundaries and petroleum geology, a new proposal. Agencia Nacional de Hidrocarburos - B\&M Exploration Ltda.

Buitrago, J. (1994). Petroleum Systems of the Neiva Area, Upper Magdalena Valley, Colombia. In: L.B. Magoon; W.G. Dow (eds.). The Petroleum System - from source to trap (pp. 483-497). AAPG, Memoir 60.

Cobbold, P.R.; Davy, P.; Gapais, D.; Rossello, E.A.; Sadybakasov, E.; Thomas, J.C.; Tondji-Biyo, J.J.; Urreiztieta, M. (1993). Sedimentary basins and crustal thickening. Sedimentary Geology, 86(1-2), 77-89. https://doi.org/10.1016/00370738(93)90134-Q

Cobbold, P.R.; Rossello, E.A.; Roperch, P.; Arriagada, C.; Gómez, L.A.; Lima, C. (2007). Distribution, timing, and causes of Andean deformation across South America. Geological Society, London, Special Publications, 272, 321-343. https://doi. org/10.1144/GSL.SP.2007.272.01.17

Cooper, M.A.; Addison, F.T.; Alvarez, R.; Coral, M.; Graham, R.H.; Hayward, A.B.; Howe, S.; Martinez, J.; Naar, J.; Peñas, R.; Pulham, A.J.; Taboada, A. (1995). Basin development and tectonic history of the Llanos Basin, Eastern Cordillera and Magdalena Valley, Colombia. AAPG Bulletin, 79(10), 1421-1443. https:// doi.org/10.1306/7834D9F4-1721-11D78645000102C1865D

Cossio, U.; Rodríguez, G.; Rodríguez, M. (1995). Geología de la Plancha 283 Purificación. Escala 1:100.000. INGEOMINAS.

Crozier, M.J. (1986). Landslides: causes, consequences and environment. Croom Helm.

Cruden, D.M.; Varnes, D.J. (1996). Landslide types and processes. In: A.K. Turner; R.L. Schuster (eds). Landslides investigation and mitigation (pp. 36-75). US National Research Council. Special Report 247, Chapter 3.

De Freitas, M.G. (2001). Exploring for subthrust traps in a transpressional setting - A review of unsuccessful results and strategies for improvement in the Upper Magdalena Valley of Colombia. AAPG Hedberg Conference, Mendoza, Argentina.

De Freitas, M.G.; Vidal, G.; Mantilla, M. (2006). Structural evolution and hydrocarbon entrapment in the Balcon field area, Upper Magdalena Valley, Colombia. IX Simposio Bolivariano de Exploración Petrolera en Cuencas Subandinas. Cartagena, Colombia. https://doi. org/10.3997/2214-4609-pdb.111.193

Dikau, R.; Brunsdsen, D.; Schrott, L.; Ibsen, M.K. (1996). Landslides recognition: identification, movement and causes. John Wiley \& Sons. 
Dingle, R.V. (1977). The anatomy of a large submarine slump on a sheared continental margin (SE Africa). Journal of the Geological Society, 134(3), 293310. https://doi.org/10.1144/gsjgs.134.3.0293

Easterbrook, D.J. (1993). Surfaces processes and landforms. (2nd ed). Prentice Hall.

Glade, T.; Anderson, M.; Crozier, M.J. (2012). Landslide hazard and risk. John Wiley \& Sons. https://doi.org/10.1002/9780470012659

Gómez, E.; Jordan, T.E.; Allmendinger, R.W.; Hegarty, K.; Kelley, S.; Heizler, M. (2003). Controls on architecture of the Late Cretaceous to Cenozoic southern Middle Magdalena Valley Basin, Colombia. GSA Bulletin, 115(2), 131-147. https:// doi.org/10.1130/0016-7606(2003)115\%3C0131: COAOTL\%3E2.0.CO;2

Gostelow, T.P. (1991). Rainfall and landslides. In: M.E. Almeida-Teixeira; R. Fantechi; R. Oliveira; A. Gomes-Coelho (eds.). Prevention and control of landslides and other mass movements (pp. 139161). Commission of the European Communities. Report EUR 12918.

Girty, G.H. (2009). Perilous Earth: Understanding Processes behind Natural Disasters. Chapter 7, Montezuma Publishing.

Hansen, M.C. (2000). Earthquakes and seismic risk in Ohio. Ohio Department of Natural Resources, Division of Geological Survey.

Hennings, P.; Olson, J.; Thompson, L. (2000). Combining outcrop data and three-dimensional structural models to characterize fracture reservoirs: an example from Wyoming. $A A P G$ Bulletin, 84(6), 830-849. https://doi.org/10.1306/ A967340A-1738-11D7-8645000102C1865D

Hergarten, S.; Robl, J.; Stüwe, K. (2014). Extracting topographic swath profiles across curved geomorphic features. Earth Surface Dynamics, 2, 97-104. https://doi.org/10.5194/esurf-2-97-2014

Higuera, D.A. (2012). Modelo petrofísico integrado del Grupo Guadalupe, aplicado al Campo Matachín Norte. MSc. Thesis, Universidad Nacional de Colombia, Bogotá, Colombia.
Hungr, O.; Leroueil, S.; Picarelli, L. (2013). The Varnes classification of landslide types, an update. Landslides 11, 167-194. https://doi.org/10.1007/ s10346-013-0436-y

Hutchinson, J.N. (1988). General report, morphological and geotechnical parameters if landslides in relation to Geology and Hydrogeoloy. 5th International Symposium on Landslides. Balkema, Rotterdam.

Hutchinson, J.N.; Bhandari, R.K. (1971). Undrained loading, a fundamental mechanism of mudflows and other mass movements. Géotechnique, 21(4), 353-358. https://doi.org/10.1680/ geot.1971.21.4.353

Jaimes, E.; De Freitas, M. (2006). An AlbianCenomanian unconformity in the Northern Andes: Evidence and tectonic significance. Journal of South American Earth Sciences, 21(4), 466-492. https://doi.org/10.1016/j.jsames.2006.07.011

Leroueil, S.; Locat, J.; Vaunat, J.; Picarelli, L.; Lee, H.; Faure, R. (1996). Geotechnical characterization of slope movements. In: K. Senneset (ed.) Landslides. Balkema, Rotterdam.

Mojica, J.; Franco, R. (1990). Estructura y evolución tectónica del Valle Medio y Superior del Magdalena, Colombia. Geología Colombiana, 17, 41-64.

Montes, C.; Hatcher, R.; Restrepo-Pace, P. (2005). Tectonic reconstruction of the northern Andean blocks: Oblique convergence and rotations derived from the kinematics of the Piedras-Girardot area, Colombia. Tectonophysics, 399(1-4), 221-250. https://doi.org/10.1016/j.tecto.2004.12.024

Mora, A.; Mantilla, M.; De Freitas, M. (2010). Cretaceous paleogeography and sedimentation in the Upper Magdalena and Putumayo Basins, Southwestern Colombia. Search and Discovery, Article \#50246, AAPG.

Nemčok, A.; Pašek, J.; Rybáŕ, J. (1972). Classification of landslides and other mass movements. Rock Mechanics, 4, 71-78. https://doi.org/10.1007/ BF01239137 
Ng, K.S.; Chew, Y.M. (2019). Slope stability analysis of embankment over stone column improved ground. Journal of Engineering Science and Technology, 14(6), 3582-3596.

Pfiffner, O.A. (2017). Thick-skinned and thin-skinned tectonics: A global perspective. Geosciences, 7(3). https://doi.org/10.3390/geosciences7030071

Price, N.J.; Cosgrove, J.W. (1990). Analysis of geological structures. Cambridge University Press.

Ramsay, J.G.; Huber, M.I. (1983). The techniques of modern structural geology: strain analyses. Academic Press.

Rincón, G.; Garzón, J.C.; de Moraes, J.J. (2003). Campo Guando, Primer Descubrimiento de la Antesala del Siglo XXI en el Valle Superior del Magdalena, Colombia. 8th Simposio Bolivariano - Exploración Petrolera en las Cuencas Subandinas. Cartagena, Colombia.

Rossello, E.A. (2001). Sistemas tectónicos transcurrentes: una síntesis de sus condiciones mecánicas y aplicaciones geoeconómicas. En: J.M. Cortés; E.A. Rossello; L. Dalla-Salda (eds.). Avances en Microtectónica (pp. 1943). Asociación Geológica Argentina Serie D: Publicación Especial No. 5.

Rossello, E.A.; Saavedra, J.L. (2016). Relaciones estructurales entre el cabalgamiento Boquerón y deslizamientos gravitatorios en el Campo Guando (Valle Superior del Magdalena, Colombia). XII Simposio Bolivariano de Cuencas Subandinas, Bogotá, Colombia.

Sassa, K. (1999). Introduction. In: K. Sassa (ed). Landslides of the world (pp. 3-18). Kyoto University Press.

Sarmiento, L.F.; Rangel, A. (2004). Petroleum systems of the Upper Magdalena Valley, Colombia. Marine and Petroleum Geology, 21(3), 373-391. https://doi.org/10.1016/j.marpetgeo.2003.11.019

Sarmiento-Rojas, L.F.; Van Wess, J.D.; Cloetingh, S. (2006). Mesozoic transtensional basin history of the Eastern Cordillera, Colombian Andes:
Inferences from tectonic models. Journal of South American Earth Sciences, 21, 383-411. https:// doi.org/10.1016/j.jsames.2006.07.003

Schamel, S. (1991). Middle and Upper Magdalena Basins, Colombia. In: K.T. Biddle (ed.). Active margin basins (pp. 283-301). Chapter 10. AAPG, Memoir, 52.

Schuster, R.L.; Salcedo, D.A.; Valenzuela, L. (2002). Overview of catastrophic landslides of South America in the twentieth century. In: S.G. Evans; J.V. DeGraff (eds.). Catastrophic Landslides: effects, occurrence, and mechanisms (pp. 1-34). The Geological Society of America. Reviews in Engineering Geology, vol. XV. https://doi. org/10.1130/REG15-p1

Seed, H.B.; Wilson, S.D. (1967). The Turnagain Heights landslide in Anchorage, Alaska. American Society of Civil Engineering. Journal of the Soil Mechanics and Foundations Division, ASCE, 93, 325-353.

Serra, O. (2008). Well logging Handbook. Technip Editions.

Sharpe, C.F. (1938). Landslides and related phenomena. Columbia University Press.

Terzaghi, K.; Peck, R.B. (1967). Soil mechanics in engineering practice. (2nd Ed.). Wiley.

Tiampo, K.F.; González, P.J.; Samsonov, S.S. (2013). Results for aseismic creep on the Hayward fault using polarization persistent scatterer InSAR. Earth and Planetary Science Letters, 367, 157165. https://doi.org/10.1016/j.epsl.2013.02.019

Tofani, V.; Raspini, F.; Catani, F.; Casagli, N. (2013). Persistent Scatterer Interferometry (PSI) technique for landslide characterization and monitoring. Remote Sensing, 5(3), 1045-1065. https://doi.org/10.3390/rs5031045

Toro, J.; Roure, F.; Bordas-Le Floch, N.; Le CornecLance, S.; Sassi, W. (2004). Thermal and kinematic evolution of the Eastern Cordillera fold and thrust belt, Colombia. In: R. Swennen; F. Roure; J.W. Granath (eds.). Deformation, fluid flow, and reservoir appraisal in foreland fold and 
thrust belts (pp. 79-115). AAPG Hedberg Series.

Uenzelmann-Neben, G.; Huhn, K. (2009). Sedimentary deposits on the southern South African continental margin: Slumping versus non-deposition or erosion by oceanic currents? Marine Geology, 266(1-4), 65-79. https://doi.org/10.1016/j. margeo.2009.07.011

Varnes, D.J. (1958). Tipos y procesos de deslizamientos de tierra. En: E.B. Eckel (ed.). Derrumbes y prácticas de ingeniería (pp. 20-47). Junta de Investigación de Carreteras. 29, Publicación 544 de NAS NRC.

Varnes, D.J. (1978). Slope movement types and processes. In: R.L. Schuster; R.J. Krizek (eds). Landslides, analysis and control (pp. 11-33). Special report 176: Transportation research board, National Academy of Sciences. Chapter 2.

Waltham, A.C.; Dixon, N. (2000). Movement of the Mam Tor landslide, Derbyshire, UK. Quarterly Journal of Engineering Geology and Hydrogeology, 33(2), 105-123. https://doi. org/10.1144/qjegh.33.2.105

Working Party for World Landslide Inventory (1995). A suggested method for describing the rate of movement of a landslide. Bulletin of the International Association of Engineering Geology, 52, 75-78. https://doi.org/10.1007/ BF02602683

Yan, G.; Yin, Y.; Huang, B.; Zhang, Z.H.; Zhu, S.N. (2019). Formation mechanism and characteristics of the Jinjiling landslide in Wushan in the Three Gorges Reservoir region, China. Landslides, 16(11), 2087-2101. https://doi.org/10.1007/ s10346-019-01234-3

Záruba, Q.; Mencl, V. (1969). Landslides and their control. Elsevier. Amsterdam, 270pp.

Trabajo recibido: mayo 27 de 2020

Trabajo aceptado: agosto 21 de 2020 